
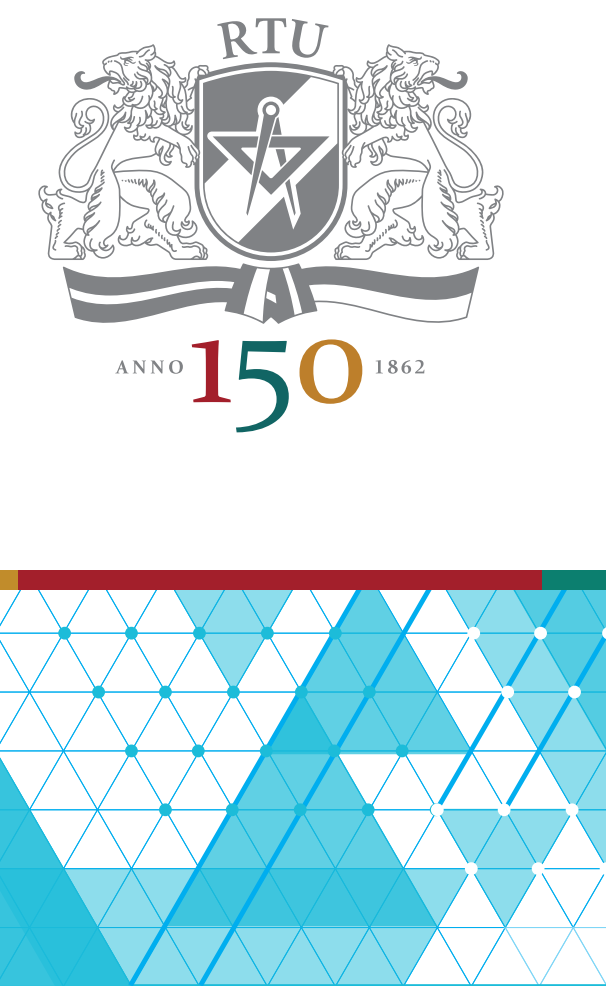

11-12 October 2012, Riga

Riga Technical University 53rd International Scientific Conference

Dedicated to the $150^{\text {th }}$ Anniversary and The 1 st Congress of World Engineers and Riga Polytechnical Institute / RTU Alumni

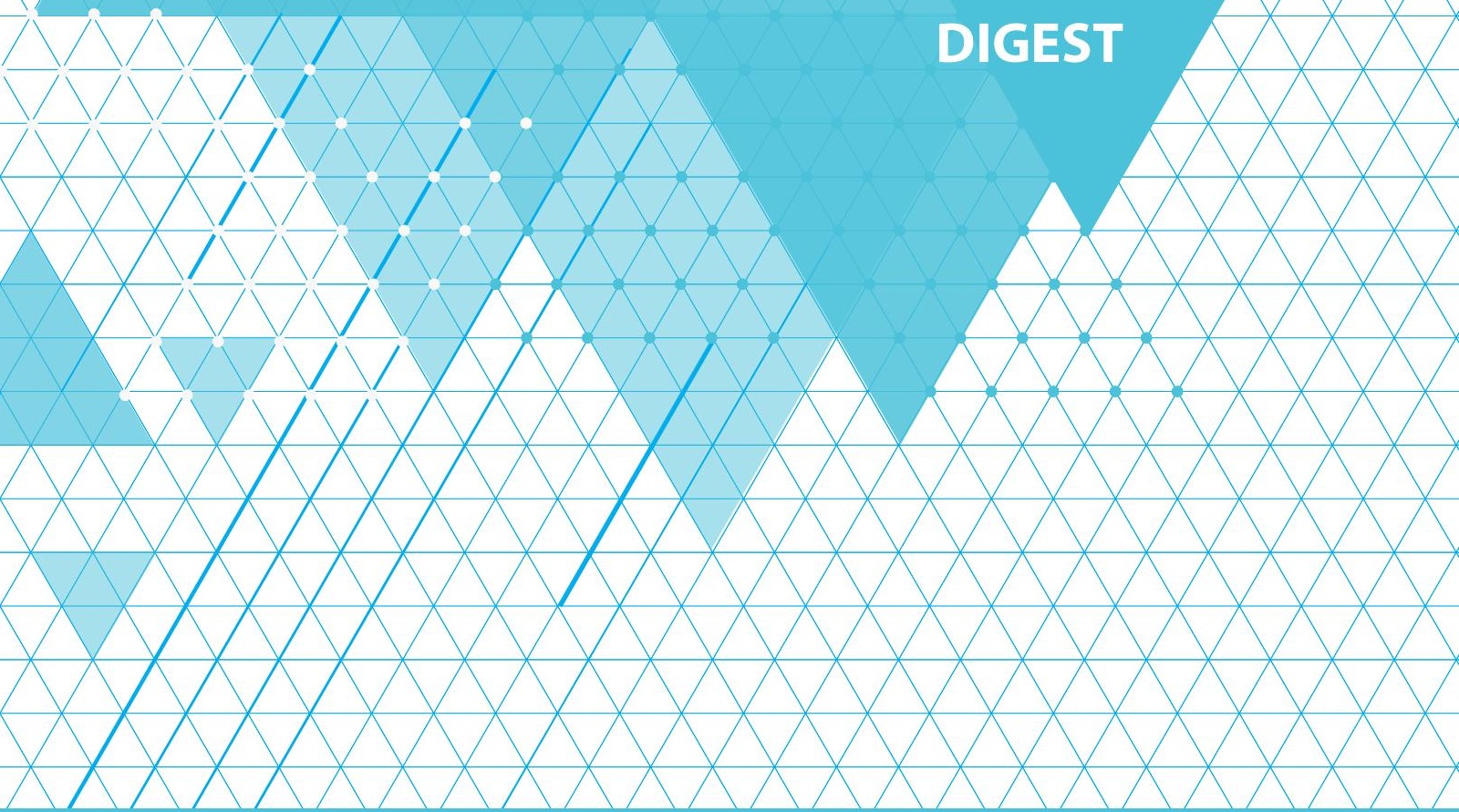




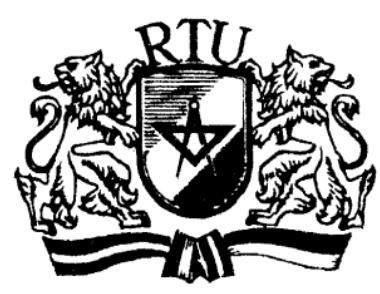

\section{RIGA TECHINICAL UNIVERSITY $53^{\text {rd }}$ INTERNATIONAL SCIENTIFIC CONFERENCE DEDICATED TO THE $150^{\text {th }}$ ANNIVERSARY AND THE $1^{\text {st }}$ CONGRESS OF WORLD ENGINEERS AND RIGA POLYTECHINICAL INSTITUTE / RTU ALUMINI}

11-12 October 2012

Rīga, Latvija 
Riga Technical University $53^{\text {rd }}$ International Scientific Conference dedicated to the $150^{\text {th }}$ anniversary and The $1^{\text {st }}$ Congress of World Engineers and Riga Polytechnical Institute / RTU Alumni

\title{
X-Ray Radiation Statistics Towards Quality Assurance In Digital Radiography
}

\author{
Lada Bumbure, Yuri Dekhtyar, Alexey Katashev, Tatyana Kirsanova and Vineta Zemite (BINI, Riga \\ Technical university)
}

Keywords - digital radiography QA, x-ray beam statistics.

\section{INTRODUCTION}

Quality assurance (QA) of $\mathrm{x}$-ray equipment is extremely important part of extensive quality control system in hospitals. Since most of diagnostic radiography is digital today, there is a great possibility to make an express quality check of $x$-ray equipment using fast digital approach.

When the signal of the detector is directly proportional to the number of the detected photons, the distribution of the signals among the detectors of the entire set after its exposure obeys Poisson statistics too. The present article is directed to explore a possibility to exploit this for quality assessment in x-ray digital radiography.

\section{MATHERIALS AND METHODS}

Digital x-ray machine "Digital Diagnost" was in use. The digital flat-panel x-ray detector "Pixium 4600" detector was employed [1]. The x-ray images were acquired using a manual operation mode. Both large and small focal spots of the X-ray tube were employed. The Source Detector Distance was $1 \mathrm{~m}$ and the irradiated field was collimated to $7 \times 7 \mathrm{~cm}$ for each exposure. X-ray image were collected in the DICOM format and transferred further to TIFF format to analyze brightness distribution. The brightness of each image pixel and the distribution over the brightness were used. The acquired statistic was verified to be the subject of the Poisson or Gauss distributions [2]. The KolmogorovSmirnov criterion $\lambda$ was employed [3]. The criterion $\lambda$ was compared with the tabulated value $\lambda_{\mathrm{t}}$ at the significance level 0.05 . If $\lambda<\lambda_{\mathrm{t}}$ the hypotheses on the trusting statistics was accepted. Thus the criterion $\lambda$ was the index that statistics corresponds to the Poisson law (higher value of $\lambda$ means that statistics less match the Poisson law). The theoretical Poisson and Gauss distributions were derived employing the parameters calculated from the experiment (average, standard deviation). This was compared with the tabulated value $\lambda_{t}$ at the significance level 0.05 . If $\lambda<\lambda_{t}$ the hypotheses on the trusting statistics was accepted. Thus the criterion $\lambda$ was the index that statistics corresponds to the Poisson law (higher value of $\lambda$ means that statistics less match the Poisson law). The theoretical Poisson and Gauss distributions were derived employing the parameters calculated from the experiment (average, standard deviation).

\section{RESULTS}

The cumulative distribution functions (CDF) brightness was found for different size areas for different kilovolts and focuses (Fig 3) on the brightness analyses base.

The results show that CDF conform Poisson distribution best when the $\mathrm{x}$-ray image is acquired at $81 \mathrm{kV}$, small focus and the 100x100 pixels large.

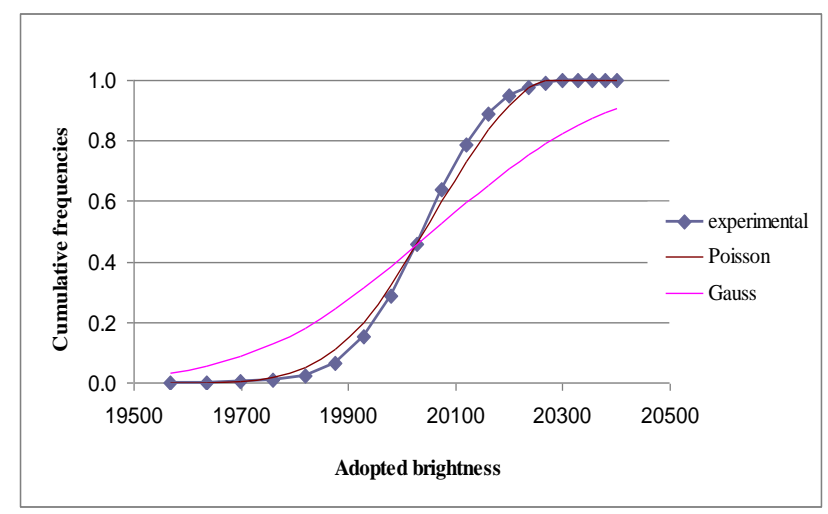

Fig. 3 The CDF for small focus, $81 \mathrm{kV}, 100 \times 100$ pixels area

When milliampers $(\mathrm{mA})$ were enlarged the value of $\lambda$ became smaller (Fig.10).

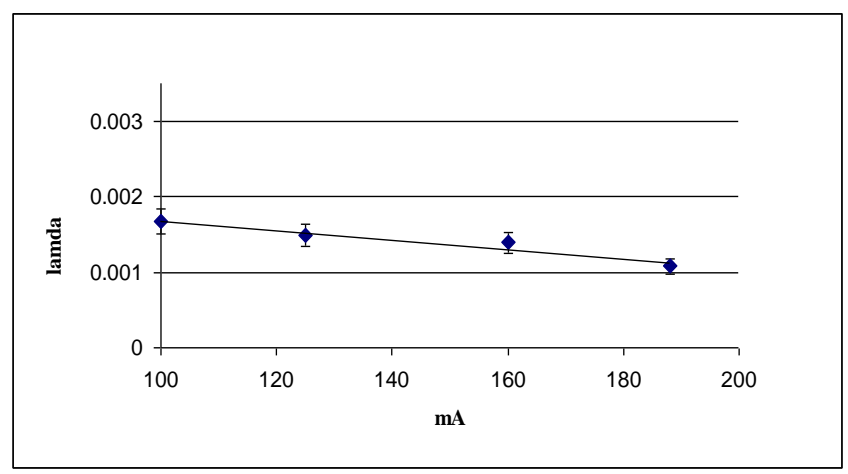

Fig. 10 Parameter $\lambda$ in dependence on Ma

\section{CONCLUSION}

The Poisson statistics based approach to analyze brightness statistics of the digital image is demonstrated to estimate quality of $x$-ray digital radiography machines. The approach could be in use by the medical staff for the express day-to-day monitoring of the $\mathrm{x}$-ray digital radiography machines quality deviations.

\section{REFERENCES}

[1] http://www.trixell.com/html-gb/products/interne/pixium_key.html\#\#

[2] Principles of statistics; M.G.Blumer; Dover publ., Inc., NY, 1979, $253 \mathrm{p}$.

[3] Математическая статистика; В.М.Иванова, В.Н.Калинина и др.; Москва; Высшая школа; 1975 г.; 398 стр. (Mathematic Statistics, V. M Ivanova et al .(ed), Moscow, "Vysshaya Shkola, 1975, 398 pp.) 